\title{
Fertilization Rate and Number of Embryos on Day 2 after Intrauterine and Deep Intrauterine Insemination Using Frozen-Thawed Boar Semen in Multiparous Sows
}

\author{
Kakanang Buranaamnuay, Yodchai Panyaboriban, Padet Tummaruk, \\ and Mongkol Techakumphu
}

Department of Obstetrics, Gynaecology and Reproduction, Faculty of Veterinary Science, Chulalongkorn University, Bangkok 10330, Thailand

Correspondence should be addressed to Padet Tummaruk, padet.t@chula.ac.th

Received 16 April 2010; Accepted 23 July 2010

Academic Editor: Kyle Orwig

Copyright (C) 2011 Kakanang Buranaamnuay et al. This is an open access article distributed under the Creative Commons Attribution License, which permits unrestricted use, distribution, and reproduction in any medium, provided the original work is properly cited.

\begin{abstract}
The present study determines fertilization rate and number of embryos on Day 2 after intrauterine insemination (IUI) and deep intrauterine insemination (DIUI) using frozen-thawed (FT) boar semen in multiparous sows. Twelve crossbred Landrace $\times$ Yorkshire multiparous sows were included. The sows were inseminated at $24 \mathrm{~h}$ after oestrus detection and reinseminated every $12 \mathrm{~h}$ until ovulation took place. The inseminations were conducted using IUI with $2 \times 10^{9} \mathrm{FT}$ sperm per dose $(n=6)$ and DIUI with $1 \times 10^{9} \mathrm{FT}$ sperm per dose $(n=6)$. The sows were slaughtered at $45.1 \pm 7.2 \mathrm{~h}$ after ovulation. Embryos and unfertilized oocytes were flushed from the oviducts. IUI yielded a better fertilization rate than DIUI $(66.0 \%$ versus $31.0 \%, P<.001)$. The number of embryos was $13.5 \pm 2.7$ and $6.6 \pm 3.2$ embryos/sow in IUI and DIUI groups, respectively $(P=.08)$. The proportion of sows having unilateral fertilization was higher in the DIUI (3/5) than the IUI group (1/6). In conclusion, IUI with at least $2 \times 10^{9}$ total number of FT boar spermatozoa is recommended.
\end{abstract}

\section{Introduction}

Recently, new procedures for artificial insemination (AI) in pigs have been established, namely, intrauterine insemination (IUI) and deep intrauterine insemination (DIUI). These techniques were developed to maximize the efficacy of utilizing boar spermatozoa, especially for the vulnerable cells, for example, frozen-thawed (FT) spermatozoa [1] and sex-sorted spermatozoa [2]. Using these techniques, each insemination required 3 to 20 times less numbers of spermatozoa than conventional AI [3-5]. This is due to the fact that the loss of spermatozoa after IUI or DIUI via semen back flow and phagocytosis by polymorphonuclear leukocytes in the uterus is diminished [6,7]. It has been demonstrated that the number of spermatozoa in the sperm reservoir at $24 \mathrm{~h}$ after insemination was not different between conventional AI and IUI with a reduced number of fresh spermatozoa [4]. However, Tummaruk et al. [5] found a significantly lower number of spermatozoa recovered from the female genital tract after DIUI with a 20 -fold reduction in the sperm dose compared to conventional AI.

Under field conditions, conventional AI with a relatively high number of FT spermatozoa ( 5 to $6 \times 10^{9}$ sperm per dose) resulted in $20 \%$ to $30 \%$ lower farrowing rate (FR) and a decrease of 2 to 3 total number of piglets born per litter (TB) compared to fresh semen [8-10]. This indicates that conventional AI may not be a suitable insemination procedure for FT semen in pigs and, therefore, IUI or DIUI techniques might be appropriate for improving fertility results of FT spermatozoa. Under filed conditions, only a limited number of studies on the in vivo fertility of sows after DIUI and IUI with frozen-thawed boar semen have been conducted [1, 11, 12]. Roca et al. [11] found that a single AI by DIUI with $1 \times 10^{9}$ FT spermatozoa in hormonally treated sows resulted in $78 \% \mathrm{FR}$ and $9.3 \mathrm{~TB}$, which were not significantly different from those achieved after DIUI 
with fresh spermatozoa (76\% FR and 9.6 TB). In addition, Bolarín et al. [1] found that a FR of over $80 \%$ and 10 TB could be achieved after DIUI with $1 \times 10^{9}$ FT spermatozoa in spontaneously-ovulating sows if the insemination was performed close to the time of ovulation. For IUI, Mezalira et al. [6] found that both the pregnancy rate, determined at 20 to 23 days after IUI using real-time B-mode ultrasonography, and the number of embryos at 34 to 40 days of gestation tended to be lower after IUI using extended fresh semen with $0.25 \times 10^{9}$ spermatozoa (78.6\% pregnancy rate, 12.8 embryos per sow) compared with 0.5 to $1 \times 10^{9}$ spermatozoa $(85.7$ to $88.9 \%$ pregnancy rate, 14.3 to 14.5 embryos per sow). The authors suggested that IUI should be conducted with at least $0.5 \times 10^{9}$ fresh spermatozoa per dose [6]. Although the number of spermatozoa, fertilization rate, and number of embryos after IUI and DIUI in sows with extended fresh semen have been reported $[5,13,14]$, these reproductive parameters after IUI and DIUI with FT spermatozoa have not been carefully determined.

Under experimental conditions, the use of $150 \times 10^{6}$ extended fresh spermatozoa for DIUI in spontaneous ovulating sows resulted in a higher percentage of partial and unilateral fertilizations and a lower percentage of viable embryos than conventional AI [13]. In addition, Tummaruk and Tienthai [14] demonstrated that DIUI with $150 \times$ $10^{6}$ spermatozoa per dose resulted in a lower number of spermatozoa in the sperm reservoir at $24 \mathrm{~h}$ after insemination compared with conventional AI and IUI. These studies imply that either sperm distribution or number of fertilized embryos retrieved after IUI or DIUI with a certain number of spermatozoa per dose should be carefully determined before practical implementation. The fertilization rate and number of embryos after the use of either IUI or DIUI techniques for insemination with FT boar spermatozoa has not been investigated. The objective of the present study was to evaluate fertilization and number of embryos on Day 2 after IUI and DIUI using FT boar semen in multiparous sows.

\section{Materials and Methods}

2.1. Animals. The experiment was conducted at an experimental unit at the Farm Animal Hospital, Faculty of Veterinary Science, Chulalongkorn University, Nakorn Pathom, Thailand. Animal welfare and treatment were approved by the faculty's ethical committee (Animal use protocol no. 0731055). Fourteen Landrace $\times$ Yorkshire crossbred sows with parity numbers 8 to 14 were brought from a commercial pig herd to the experimental unit at weaning. All sows were allocated to individual pens adjacent to an adult boar. The sows were fed with a commercial ration (Betagro 306, Betagro-Agro group Co., Ltd., Nakorn-pathom, Thailand) twice a day. The feed contained approximately 15\% crude protein, 3,000 kcal/kg metabolisable energy and 0.9\% lysine, as-fed basis. Water was provided ad libitum via water nipple.

Detection of oestrus and ovulation: The sows were allowed to have snout-to-snout contact with a mature boar daily from one day after weaning onwards. Pro-oestrus signs, that is, reddening and swelling of the vulva, were determined twice a day $(\mathrm{am} / \mathrm{pm})$. Once the pro-oestrous signs were found, the sows were carefully examined for standing oestrus every $4 \mathrm{~h}$ by allowing the sows to have contact with a mature boar for 5 to $10 \mathrm{~min}$; thereafter, the back pressure test was performed. Sows that exhibited a standing reflex were considered to be in oestrus. The onset of oestrus was assigned as $2 \mathrm{~h}$ before the first standing reflex was detected. Only the sows that showed standing oestrus within 7 days after weaning were included in the experiment. Ovulation was investigated every $4 \mathrm{~h}$, starting from $24 \mathrm{~h}$ after oestrus, using transrectal ultrasonography (Echo camera SSD-550, Aloka co. ltd., Tokyo, Japan). The time of ovulation was defined as $2 \mathrm{~h}$ after the last detection of follicles on the ovaries $[15,16]$.

2.2. Semen Collection and Cryopreservation. The semen used for all inseminations was obtained from a Yorkshire boar. Sperm-rich fraction was collected using the gloved-hand method. Semen was kept in an insulated thermos flask during transport to the laboratory and accomplished within $40 \mathrm{~min}$ after collection. Only ejaculates with $\geq 70 \%$ motile spermatozoa were included. Ejaculates were cryopreserved using the procedure previously described by Buranaamnuay et al. [12]. Briefly, the sperm-rich fractions were extended $(1: 1, \mathrm{v} / \mathrm{v})$ in Beltsville Thawing Solution (BTS; Minitüb Ltd., Abfüll-und Labortechnik GmbH and Co. KG, Tiefenbach, Germany) and cooled to $15^{\circ} \mathrm{C}$ for $2 \mathrm{~h}$. After centrifugation at $800 \times \mathrm{g}$ for $10 \mathrm{~min}$, the pellets were diluted in lactoseegg yolk (LEY) extender $(80 \mathrm{~mL}$ of $11 \%$ lactose solution and $20 \mathrm{~mL}$ egg yolk) to a concentration of $1.5 \times 10^{9}$ cells per $\mathrm{mL}$. After further cooling to $5^{\circ} \mathrm{C}$ over a 90 -minute period, diluted sperm were resuspended with another extender (LEY extender, 9\% glycerol and 1.5\% Equex STM Paste; Nova Chemical Sales Inc., Scituate, MA, USA) to a final concentration of $1 \times 10^{9}$ sperm per $\mathrm{mL}$. The processed sperm were packed into 0.5 PVC-french straws (Bio-Vet, Z.I. Le Berdoulet, France) and frozen by placing in liquid nitrogen $\left(\mathrm{LN}_{2}\right)$ vapor approximately $3 \mathrm{~cm}$ above the level of $\mathrm{LN}_{2}$ for $20 \mathrm{~min}$ before the straws were plunged into $\mathrm{LN}_{2}$.

2.3. Thawing. Thawing was achieved by immersing the straws in $50^{\circ} \mathrm{C}$ of water for $12 \mathrm{sec}$. Immediately after thawing, the semen was diluted (1:4) with an extender consisting of 95\% BTS and 5\% LEY extender. The addition of LEY extender prevents the sperm from sticking to the glass and was used during motility analysis. The extended thawed semen was incubated in a $38^{\circ} \mathrm{C}$ water-bath for $30 \mathrm{~min}$ before evaluation of sperm motility. The motility of spermatozoa was estimated subjectively using a light microscope at 400x magnification. FT semen containing $\geq 35 \%$ motile spermatozoa was used for insemination.

2.4. Insemination. The sows were randomly assigned at weaning into two groups, IUI and DIUI, according to ear tag and parity number and were inseminated with FT boar semen. The sows were inseminated at $24 \mathrm{~h}$ after the onset of oestrus and repeated every $12 \mathrm{~h}$ until ovulation took place. Both IUI and DIUI were conducted in gestation crates. 
A deep insemination device (Deep goldenpig catheter, IMV Technologies, L'Aigle, France) was used for IUI [17]. After the extended FT semen was inseminated, $2 \mathrm{~mL}$ of BTS extender was flushed to force remaining semen in the catheter. For DIUI, a conventional AI catheter (Goldenpig, IMV Technologies, L'Aigle, France) was manipulated through the vagina into the cervix. Thereafter, a DIUI device (length $180 \mathrm{~cm}$, out diameter $4 \mathrm{~mm}$, and working inner channel of $1.8 \mathrm{~mm}$; Firflex, Magapor, Ejea de los Caballeros, Spain) was inserted through the AI catheter, handled through the cervix and propelled forward along one uterine horn. A syringe containing $1 \times 10^{9}$ total sperm in $10 \mathrm{~mL}$ of BTS was connected to the device. After insemination, $2 \mathrm{~mL}$ of BTS extender was flushed before slowly removing the device.

2.5. Recovery of Embryos and Oocytes. Sows were slaughtered at about $48 \mathrm{~h}$ after ovulation. The reproductive organs, that is, the uterine horns, the oviducts, and the ovaries were collected. The number of corpora lutea (CL) was counted on both ovaries and was assumed to be the number of ovulations. Each oviduct was separated from the uterus and flushed with $20 \mathrm{~mL}$ of TCM 199 Hepes $38^{\circ} \mathrm{C}$ from the infundibulum through the uterotubal junction in order to obtain embryos and oocytes. Examination of the retrieved embryos and oocytes was performed under a stereomicroscope (40x).

2.6. Definition. The recovery rate was defined as the number of embryos and oocytes recovered divided by the number of CL, multiplied by 100 . Fertilization was assumed when at least 2 cells-stage embryos were found. The fertilization rate was determined as the number of embryos ( $\geq 2$ cells) divided by the sum of embryos and oocytes recovered and multiplied by 100 . Bilateral fertilization was assumed when embryos could be retrieved from both oviducts, and unilateral fertilization was assumed when embryos were found in only the unilateral side of the oviduct. The conception rate was defined as the number of sows having $\geq 4$ embryos divided by the total number of sows inseminated, multiplied by 100 .

2.7. Statistical Analysis. The statistical analysis was performed using Statistical Analysis System (SAS) version 9.0 (SAS Institute Inc., Cary, NC, USA). The numbers of CL, embryos and oocytes were analyzed using the General Linear Model (GLM) procedure of SAS. The model included insemination groups (IUI versus DIUI) as an independent variable. Least-square means were compared between groups using the least significant different (LSD) test. The numbers of CL between the left and the right ovaries were compared using paired $t$-test. Recovery rate, fertilization rate and conception rate were compared between IUI and DIUI groups using Fisher's exact test. Differences were considered to be significant at $P<.05$.

\section{Results}

Of the 14 sows, one sow was excluded because the weaningto-oestrus interval was $>7$ days and one sow was excluded
TABLE 1: Means \pm standard error of the mean (SEM) of weaningto-oestrus interval, oestrus-to-ovulation interval, interval from last insemination to ovulation, interval from ovulation to slaughter, number of inseminations, number of ovulations, recovery rate, fertilization rate, percentage of sows having $\geq 1$ embryo, conception rate and percentage of unilateral fertilization after intrauterine (IUI) and deep intra-uterine insemination (DIUI) using frozenthawed boar semen in multiparous sows.

\begin{tabular}{|c|c|c|}
\hline \multirow[t]{2}{*}{ Parameters } & \multicolumn{2}{|c|}{ Insemination procedure } \\
\hline & IUI & DIUI \\
\hline Number of sows & 6 & 6 \\
\hline $\begin{array}{l}\text { Weaning-to-oestrus interval } \\
\text { (h) }\end{array}$ & $68.0 \pm 3.4^{\mathrm{a}}$ & $72.6 \pm 6.4^{\mathrm{a}}$ \\
\hline $\begin{array}{l}\text { Oestrus-to-ovulation interval } \\
\text { (h) }\end{array}$ & $48.6 \pm 3.1^{\mathrm{a}}$ & $50.3 \pm 5.8^{\mathrm{a}}$ \\
\hline $\begin{array}{l}\text { Interval from last } \\
\text { insemination to ovulation (h) }\end{array}$ & $1.4 \pm 0.7^{\mathrm{a}}$ & $4.3 \pm 1.9^{\mathrm{a}}$ \\
\hline $\begin{array}{l}\text { Interval from ovulation to } \\
\text { slaughter (h) }\end{array}$ & $46.6 \pm 2.4^{\mathrm{a}}$ & $43.8 \pm 4.7^{\mathrm{a}}$ \\
\hline Number of inseminations & $3.0 \pm 0.0^{\mathrm{a}}$ & $3.1 \pm 0.3^{\mathrm{a}}$ \\
\hline Number of ovulations & $23.8 \pm 2.5^{\mathrm{a}}$ & $21.3 \pm 1.6^{\mathrm{a}}$ \\
\hline Number of embryos & $13.5 \pm 2.7^{\mathrm{a}}$ & $5.5 \pm 3.2^{\mathrm{a}}$ \\
\hline Recovery rate $(\%)$ & $\begin{array}{c}85.3 \\
(122 / 143)^{\mathrm{a}}\end{array}$ & $\begin{array}{c}82.0 \\
(105 / 128)^{\mathrm{a}}\end{array}$ \\
\hline Fertilization rate (\%) & $\begin{array}{c}66.4 \\
(81 / 122)^{\mathrm{a}}\end{array}$ & $\begin{array}{c}31.4 \\
(33 / 105)^{b}\end{array}$ \\
\hline Left oviduct & $\begin{array}{c}70.9 \\
(39 / 55)\end{array}$ & $\begin{array}{c}26.7 \\
(12 / 45)\end{array}$ \\
\hline Right oviduct & $\begin{array}{c}62.7 \\
(42 / 67)\end{array}$ & $\begin{array}{c}35.0 \\
(21 / 60)\end{array}$ \\
\hline $\begin{array}{l}\text { Percentage of sows having } \geq 1 \\
\text { embryo }(\%)\end{array}$ & $\begin{array}{l}100.0 \\
(6 / 6)^{\mathrm{a}}\end{array}$ & $83.3(5 / 6)^{\mathrm{a}}$ \\
\hline Conception rate (\%) & $83.3(5 / 6)$ & $33.3(2 / 6)$ \\
\hline $\begin{array}{l}\text { Percentage of unilateral } \\
\text { fertilization }(\%)\end{array}$ & $16.7(1 / 6)$ & $60(3 / 5)$ \\
\hline
\end{tabular}

$\overline{\mathrm{a}, \mathrm{b}}$ Means with different superscripts within rows differed significantly $(P<$ $.001)$.

because the recovery rate after the embryo collection was below $20 \%$. Therefore, the results in this study were based on 12 sows (IUI, $n=6$ and DIUI, $n=6$ ) (Table 1 ).

Of the 12 sows, the weaning-to-oestrus interval was 70.3 $\pm 12.2 \mathrm{~h}$ (range 52 to $96 \mathrm{~h}$ ). Ovulation took place at 49.6 $\pm 10.9 \mathrm{~h}$ (range 35.0 to $72.0 \mathrm{~h}$ ) after the onset of oestrus. The sows were slaughtered at $45.1 \pm 7.2 \mathrm{~h}$ (range 31 to $54 \mathrm{~h}$ ) after ovulation. On average, number of ovulations was 23.8 \pm 6.2 and $21.3 \pm 4.0$ in IUI and DIUI groups, respectively, $(P=.424)$ (Table 1). The number of ovulations from the left and the right ovaries did not differ significantly $(10.5 \pm 2.9$ and $12.1 \pm 5.8$ for the left and right ovary, resp., $P=.488$ ).

The recovery rate, fertilization rate, and number of embryos in the IUI and DIUI groups are presented in Table 1 . The overall recovery rate was $83.3 \%$. The recovery rate did not differ significantly between IUI $(85.3 \%)$ and DIUI $(82.0 \%)$ groups (Table 1$)$. The fertilization rate did not differed significantly between the left and the right sides of the oviducts in both IUI and DIUI groups (Table 1). Fertilization occurred in all of the sows in the IUI group 
$(6 / 6,100 \%)$ and in 5 out of 6 sows in the DIUI group $(5 / 6$, $83.3 \%)(P=1.00)$. The fertilization rate after IUI $(81 / 122$, $66.4 \%)$ was higher than DIUI $(31 / 105,31.4 \%)(P<.001)$. Fertilization took place on both sides of the oviducts in 5 out of 6 sows in the IUI group $(5 / 6,83.3 \%)$ and in 2 out of 5 sows in the DIUI group $(2 / 6,33.3 \%)(P=.242)$. The number of embryos after IUI (13.5 \pm 2.7 embryos per sow $)$ tended to be higher than after DIUI $(5.5 \pm 3.2$ embryos per sow $)$ $(P=.08)$. The stages of embryos retrieved were between 2 and 8 cells.

On average, the interval from last insemination to ovulation was $3.0 \pm 4.1 \mathrm{~h}$ (range 0 to $12 \mathrm{~h}$ ). The interval from last insemination to ovulation in the IUI group was 1.4 $\pm 1.5 \mathrm{~h}$ (range 0 to $3 \mathrm{~h}$ ) and in the DIUI group was $4.3 \pm$ $5.2 \mathrm{~h}$ (range 0 to $12 \mathrm{~h})(P=.257)$ (Table 1$)$. In the DIUI group, the interval from last insemination to ovulation of more than $6 \mathrm{~h}$ was observed in 2 out of 6 sows. Of these two sows, one sow had unfertilized oocytes on both sides of the oviduct and another sow had embryos on one side of the oviduct (unilateral fertilization). After excluding these two sows, the fertilization rate in the IUI group remained higher than the DIUI group ( $66.4 \%$ versus $50.0 \%, P=.039)$. Additionally, after exclusion of the two sows which ovulated later than $6 \mathrm{~h}$ after DIUI, the average number of embryos per sow improved slightly from 5.0 to 8.0 embryos per sows $(P=.289)$.

\section{Discussion}

The present study demonstrates that fertilization could possibly occur on both sides of the sow's oviducts after either IUI or DIUI in some sows. This indicates the feasibility of using a low number of FT spermatozoa for artificial insemination in pig. Using either IUI or DIUI procedures, the sperm can be transported via the genital tract of the females to successfully fertilize the oocytes. This finding is in agreement with previous studies in which extended fresh semen was used for IUI [4] and DIUI [3, 5, 13]. Martinez et al. [3] stated that spermatozoa deposited in only one uterine horn by DIUI can migrate to the contralateral oviduct and fertilize the oocytes via both transuterine and transperitoneal migrations. Nevertheless, DIUI with $150 \times 10^{6}$ chilled sperm diluted in $10 \mathrm{~mL}$ extender per dose in spontaneously ovulating sows resulted in unilateral and partial fertilizations in some sows 10,24]. This probably resulted from too low spermatozoa number and/or semen volume used. However, when the number of spermatozoa was increased to $600 \times 10^{6}$ sperm, no evidence of unilateral fertilization was observed [13]. All of these findings suggest that when DIUI is performed, the number of spermatozoa and/or the volume of the extended semen have to be high enough to establish an adequate sperm population in the sperm reservoirs so that fertilization could be accomplished in both oviducts. In the present study, a low fertilization rate, unilateral fertilization, and low number of embryos per sow were observed in the DIUI group. This was probably due to either a too low number of sperm or volume of the FT semen used.
It has been demonstrated that the FT boar spermatozoa remain viable in the female reproductive tract for $6 \mathrm{~h}$ after insemination $[7,18,19]$. In the present study, the interval from the last insemination to ovulation of more than $6 \mathrm{~h}$ was observed in 2 out of 6 sows in the DIUI group. Of these two sows, one sow had unfertilized oocytes on both sides of the oviducts and another sow had embryos on only one side of the oviduct (unilateral fertilization). Our results confirm earlier findings that the risk of incomplete fertilization or unilateral fertilization may increase when the insemination is carried out too early relative to ovulation [20, 21]. Using extended fresh spermatozoa, optimal fertilization rates and number of embryos could be obtained when insemination was performed during 0 to $24 \mathrm{~h}$ before ovulation $[18,22]$. However, unilateral fertilization has also been observed even when a single conventional AI is performed during 0 to $8 \mathrm{~h}$ before ovulation in gilts [18]. In the present study, unilateral fertilization was observed even in the sows (2 sows in the DIUI group) inseminated within $3 \mathrm{~h}$ after ovulation. Therefore, regardless of the interval from insemination to ovulation, unilateral fertilization could occur. Based on these findings, to improve fertilization and the number of embryos after DIUI with FT boar semen, both the semen volume and the total number of spermatozoa should be increased.

In the present study, the percentage of sows with unilateral fertilization was higher in the DIUI than the IUI group. This suggests that DIUI with a total number of 1 $\times 10^{9}$ FT spermatozoa per dose may not be sufficient for complete fertilization in spontaneously ovulating sows. It is well-documented that several factors are important for the formation of the functional sperm reservoir in the female oviducts, including selective binding of spermatozoa to the oviductal epithelium [23]. The sperm population that enters the sperm reservoirs depends on the number of spermatozoa inseminated $[14,24]$. Nonetheless, spermatozoa that are able to attach to the oviductal epithelium of the sperm reservoir must be viable and remain non capacitated [25-27]. In general, about $40 \%$ to $50 \%$ of the sperm population die after the freezing and thawing process [28] and some of the viable spermatozoa may lose their fertilizing capacity due to capacitation-like changes [29]. Therefore, a low number of viable sperm used in the present study may not be enough to stimulate the formation of the functional sperm reservoirs in some sows. An earlier study has demonstrated that a lower number of spermatozoa were found in the sperm reservoir at $24 \mathrm{~h}$ after DIUI with a reduced number of extended fresh spermatozoa compared to IUI and conventional AI [14].

In the present study, the number of embryos per sow in the DIUI group tended to be lower than in the IUI group. Earlier studies have found that the number of embryos and/or TB in sows inseminated using the DIUI procedure with a low number of extended fresh spermatozoa was lower than after conventional AI [5, 13, 30, 31]. These findings suggest that the low number of embryos per sow after DIUI with a relatively low number of spermatozoa might be due to incomplete and/or partial fertilization. Moreover, in the present study, the proportion of sows with at least 4 embryos tended to be higher after IUI compared to DIUI. It is speculated that a higher FR might be obtained after 
IUI with $2 \times 10^{9} \mathrm{FT}$ spermatozoa compared to DIUI with $1 \times 10^{9}$ FT spermatozoa.

In conclusion, IUI and DIUI with relatively low numbers of FT boar spermatozoa resulted in either unilateral or bilateral fertilization. The fertilization rates and number of embryos on Day 2 after IUI were higher than DIUI. Therefore, IUI with at least $2 \times 10^{9}$ total number of FT boar spermatozoa is recommended.

\section{Acknowledgments}

This project was supported by a Grant from the National Research Council of Thailand (NRCT). K. Buranaamnuay was a Ph.D. student under the Royal Golden Jubilee (RGJ) Ph.D. Program. M. Techakumphu was supported by a Grant from the CHE-TRF Senior Research Fund (RTA5080010). Language editing of the paper was coordinated by Chula Unisearch, Chulalongkorn University.

\section{References}

[1] A. Bolarín, J. Roca, H. Rodríguez-Martínez, M. Hernández, J. M. Vázquez, and E. A. Martínez, "Dissimilarities in sows' ovarian status at the insemination time could explain differences in fertility between farms when frozen-thawed semen is used," Theriogenology, vol. 65, no. 3, pp. 669-680, 2006.

[2] J. M. Vazquez, E. A. Martinez, I. Parrilla, J. Roca, M. A. Gil, and J. L. Vazquez, "Birth of piglets after deep intrauterine insemination with flow cytometrically sorted boar spermatozoa," Theriogenology, vol. 59, no. 7, pp. 1605-1614, 2003.

[3] E. A. Martinez, J. M. Vazquez, J. Roca et al., "Minimum number of spermatozoa required for normal fertility after deep intrauterine insemination in non-sedated sows," Reproduction, vol. 123, no. 1, pp. 163-170, 2002.

[4] P. Sumransap, P. Tummaruk, and A. Kunavongkrit, "Sperm distribution in the reproductive tract of sows after intrauterine insemination," Reproduction in Domestic Animals, vol. 42, no. 2, pp. 113-117, 2007.

[5] P. Tummaruk, P. Sumransap, M. Techakumphu, and A. Kunavongkrit, "Distribution of spermatozoa and embryos in the female reproductive tract after unilateral deep intra uterine insemination in the pig," Reproduction in Domestic Animals, vol. 42, no. 6, pp. 603-609, 2007.

[6] A. Mezalira, D. Dallanora, M. L. Bernardi, I. Wentz, and F. P. Bortolozzo, "Influence of sperm cell dose and postinsemination backflow on reproductive performance of intrauterine inseminated sows," Reproduction in Domestic Animals, vol. 40, no. 1, pp. 1-5, 2005.

[7] T. Wongtawan, F. Saravia, M. Wallgren, I. Caballero, and H. Rodríguez-Martínez, "Fertility after deep intra-uterine artificial insemination of concentrated low-volume boar semen doses," Theriogenology, vol. 65, no. 4, pp. 773-787, 2006.

[8] B. A. Didion and R. A. Schoenbeck, "Fertility of frozen boar semen used for AI in commercial settings," Reproduction in Domestic Animals, vol. 31, no. 1, pp. 175-178, 1996.

[9] P. O. Hofmo and I. S. Grevle, "Development and commercial use of frozen boar semen in Norway," in Boar Semen Preservation IV, L. A. Johnson and H. D. Guthrie, Eds., pp. 71-86, Allen Press, Lawrence, Kan, USA, 2000.

[10] B. M. Eriksson, H. Petersson, and H. Rodriguez-Martinez, "Field fertility with exported boar semen frozen in the new
FlatPack container," Theriogenology, vol. 58, no. 6, pp. 10651079, 2002.

[11] J. Roca, G. Carvajal, X. Lucas, J. M. Vazquez, and E. A. Martinez, "Fertility of weaned sows after deep intrauterine insemination with a reduced number of frozen-thawed spermatozoa," Theriogenology, vol. 60, no. 1, pp. 77-87, 2003.

[12] K. Buranaamnuay, T. Wongtawan, S. Masuwatana, P. Tummaruk, and M. Techakumphu, "Intra-uterine and deep intrauterine insemination using cryopreserved boar semen in spontaneously-ovulating sows," The Thai Journal of Veterinary Medicine, vol. 40, no. 2, pp. 215-219, 2010.

[13] E. A. Martinez, J. M. Vazquez, I. Parrilla et al., "Incidence of unilateral fertilizations after low dose deep intrauterine insemination in spontaneously ovulating sows under field conditions," Reproduction in Domestic Animals, vol. 41, no. 1, pp. 41-47, 2006.

[14] P. Tummaruk and P. Tienthai, "Number of spermatozoa in the crypts of the sperm reservoir at about $24 \mathrm{~h}$ after a lowdose intrauterine and deep intrauterine insemination in sows," Reproduction in Domestic Animals, vol. 45, no. 2, pp. 208-213, 2010.

[15] N. M. Soede, J. P. T. M. Noordhuizen, and B. Kemp, "The duration of ovulation in pigs, studied by transrectal ultrasonography, is not related to early embryonic diversity," Theriogenology, vol. 38, no. 4, pp. 653-666, 1992.

[16] J. N. Mburu, S. Einarsson, A. M. Dalin, and H. RodriguezMartinez, "Ovulation as determined by transrectal ultrasonography in multiparous sows: relationships with oestrous symptoms and hormonal profiles," Zentralblatt für Veterinärmedizin. Reihe A, vol. 42, no. 4, pp. 285-292, 1995.

[17] P. F. Watson and J. R. Behan, "Intrauterine insemination of sows with reduced sperm numbers: results of a commercially based field trial," Theriogenology, vol. 57, no. 6, pp. 1683-1693, 2002.

[18] D. Waberski, K. F. Weitze, T. Gleumes, M. Schwarz, T. Willmen, and R. Petzoldt, "Effect of time of insemination relative to ovulation on fertility with liquid and frozen boar semen," Theriogenology, vol. 42, no. 5, pp. 831-840, 1994.

[19] P. F. Watson, "The causes of reduced fertility with cryopreserved semen," Animal Reproduction Science, vol. 60-61, pp. 481-492, 2000.

[20] N. M. Soede, D. W. B. Steverink, P. Langendijk, and B. Kemp, "Optimised insemination strategies in swine AI," in Boar Semen Preservation IV, L. A. Johnson and H. D. Guthrie, Eds., pp. 185-190, Allen Press, Lawrence, Kan, USA, 2000.

[21] R. H. Hunter, "The effects of delayed insemination on fertilization and early cleavage in the pig," Journal of Reproduction and Fertility, vol. 13, no. 1, pp. 133-147, 1967.

[22] N. M. Soede, C. C. H. Wetzels, W. Zondag, M. A. I. De Koning, and B. Kemp, "Effects of time of insemination relative to ovulation, as determined by ultrasonography, on fertilization rate and accessory sperm count in sows," Journal of Reproduction and Fertility, vol. 104, no. 1, pp. 99-106, 1995.

[23] A. Fazeli, A. E. Duncan, P. F. Watson, and W. V. Holt, "Spermoviduct interaction: induction of capacitation and preferential binding of uncapacitated spermatozoa to oviductal epithelial cells in porcine species," Biology of Reproduction, vol. 60, no. 4, pp. 879-886, 1999.

[24] H. Rodríguez-Martínez, F. Saravia, M. Wallgren et al., "Boar spermatozoa in the oviduct," Theriogenology, vol. 63, no. 2, pp. 514-535, 2005.

[25] J. N. Mburu, S. Einarsson, N. Lundeheim, and H. RodriguezMartinez, "Distribution, number and membrane integrity of spermatozoa in the pig oviduct in relation to spontaneous 
ovulation," Animal Reproduction Science, vol. 45, no. 1-2, pp. 109-121, 1996.

[26] J. N. Mburu, H. Rodriguez-Martinez, and S. Einarsson, "Changes in sperm ultrastructure and localisation in the porcine oviduct around ovulation," Animal Reproduction Science, vol. 47, no. 1-2, pp. 137-148, 1997.

[27] P. Tienthai, A. Johannisson, and H. Rodriguez-Martinez, "Sperm capacitation in the porcine oviduct," Animal reproduction science, vol. 80, no. 1-2, pp. 131-146, 2004.

[28] M. García-Herreros, F. J. Barón, I. M. Aparicio, A. J. Santos, L. J. García-Marín, and M. C. Gil, "Morphometric changes in boar spermatozoa induced by cryopreservation," International Journal of Andrology, vol. 31, no. 5, pp. 490-498, 2008.

[29] P. F. Watson, "Recent developments and concepts in the cryopreservation of spermatozoa and the assessment of their postthawing function," Reproduction, Fertility, and Development, vol. 7, no. 4, pp. 871-891, 1995.

[30] J. M. Vazquez, E. A. Martinez, I. Parrilla, et al., "Deep intrauterine insemination in natural post-weaning estrus sows," in Proceedings of the 6th International Conference on Pig Reproduction, p. 135, Columbia, SC, USA, 2001.

[31] B. N. Day, K. Mathias, B. A. Didion, E. A. Martinez, and J. N. Caamano, "Deep intrauterine insemination in sows: first field trial in USA commercial farm with newly developed device," Theriogenology, vol. 59, p. 213, abstract, 2003. 

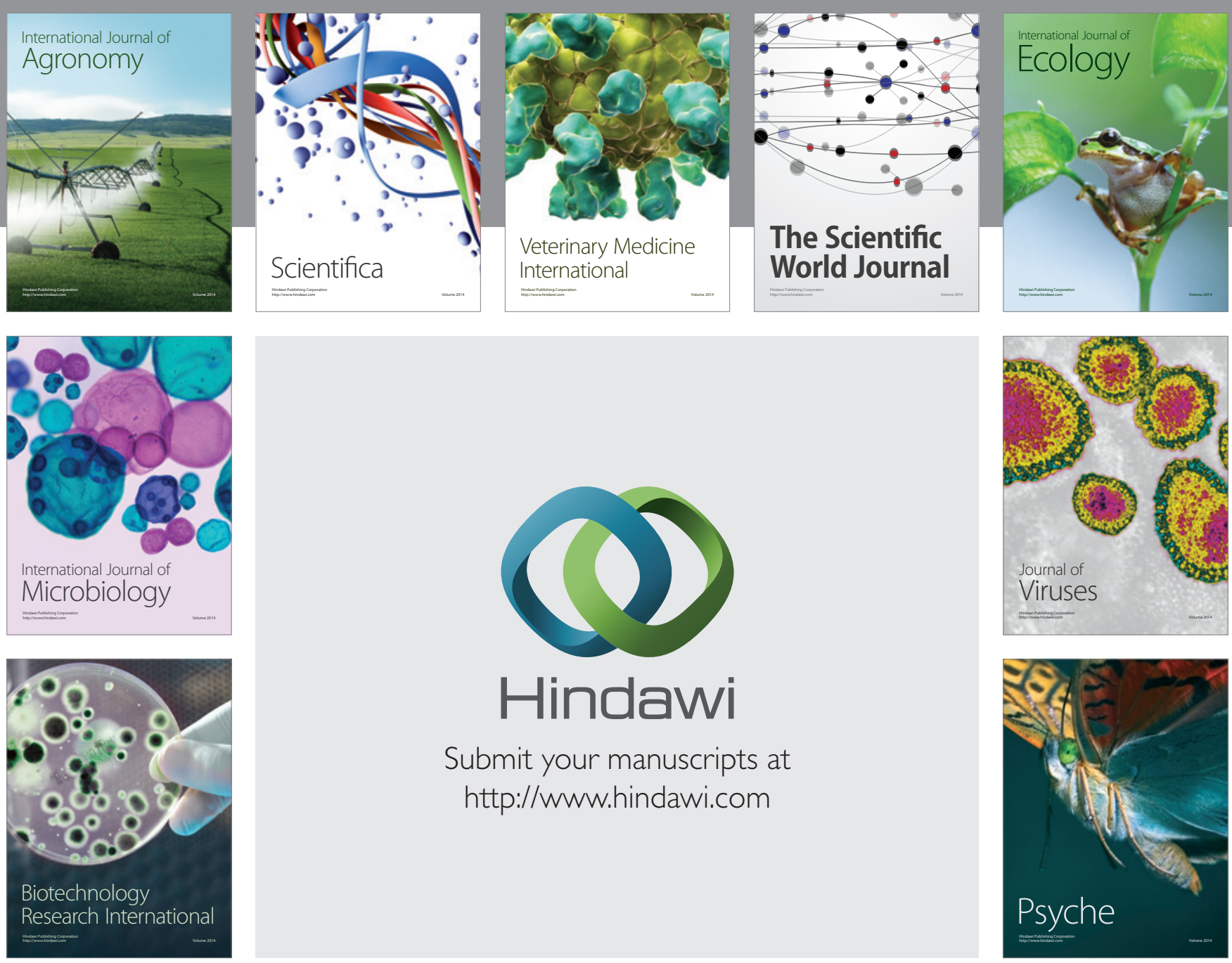

Submit your manuscripts at

http://www.hindawi.com
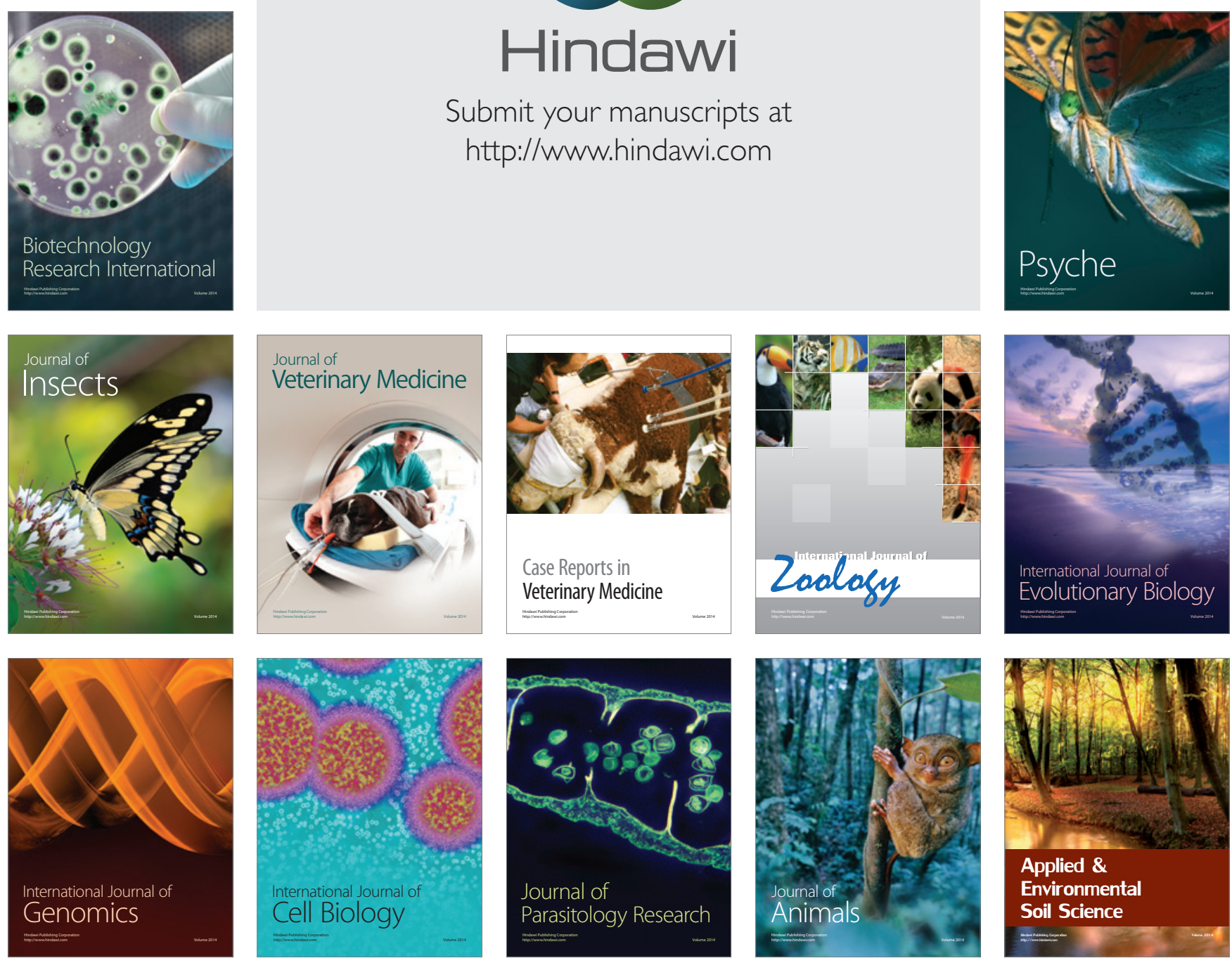